\title{
Effect of Teaching Program Regarding Care for Acute Meningitis on Nurses Performance at Emergency Unit
}

\author{
Hanaa Ahmed Mohammed ${ }^{1}$, Mona Aly Mohammed ${ }^{2}$, Naglaa Ahmed Ahmed ${ }^{3}$. \\ 1. Assistant prof. of Critical care And emergency nursing department Faculty of Nursing, Assuit University, Egypt. \\ 2. Lecturer of Critical care and emergency Nursing department, Faculty of Nursing, Assuit University, Egypt. \\ 3. Clinical Nurse Specialist at pediatric hospital Assuit University, Egypt.
}

\begin{abstract}
Background: Meningitis is defining the patients as having inflammation of the meninges with a continuous fever. The triage nurse must be fully aware of the signs and symptoms of the disease and refer the patient immediately to the emergency room physician. The aim of this study was carried out to evaluate the effect of teaching program about nursing care of acute meningitis on nurse's performance at emergency units. Subjects and method, A quasiexperimental research design was used to conduct this study at the emergency unit at assiut university hospital .Sample All available of nurses (30 nurses). Results: The results of the study present that the effectiveness of teaching program regarding nurses knowledge toward acute meningitis is a positive in post-test of teaching program. ( knowledge at pre program is $15.5 \%$. However, knowledge at post program become $48.5 \%$. Practice at pre program is $8.6 \%$.However, Practice at post program become 23.7\%). Conclusion: The majority of nurses had satisfactory knowledge and skills toward acute meningitis after applying of teaching program more than before implementation of program with statistical significant differences between pre-post teaching program. Recommendation: The study recommended that the latest guidelines of acute meningitis should be available in written format in critical and emergency units.
\end{abstract}

\section{Key words: Teaching Program, Nurse Performance, Meningitis \& Emergency Unit.}

\section{Introduction}

Meningitis is defined as an infection that causes inflammation of the meninges. The meninges are the three membranes (the dura mater, arachnoid mater, and pia mater) that line the vertebral canal and skull and enclose the brain and spinal cord. The causative organism of meningitis include bacteria, viruses, and fungi. (Leonard, 2018)

Acute Meningitis can be classified as pyogenic or bacterial Meningitis, Tuberculosis Meningitis, Aseptic Meningitis caused by virus, fungus or protozoa. (toxoplasmosis). Inflammation of meningitis may occur due to primary infection of meningitis or due to metastatic spread from nearly or distant pyogenic focus, infection may occur due to extension of local bacterial infection from sinusitis, or pyogenic fits media or from bacteremia through hematogenous. (Louis,2017)

Pyogenic Meningitis can be complicated with several neurological and systematic complications. The complication includes shock, myocarditis, status epilepticus. Section, subdural empyemas or effusion, ventriculitis, hydrocephalus or neurological defitus.

ocular palsies blindness speech problem, deafness obesity, and precocious puberty. (Marilyn, 2017)

The triage nurse must be fully aware of the signs and symptoms of the disease and refer the patient immediately to the emergency room physician. If bacterial meningitis is suspected the antibiotics should be started even in the absence of laboratory results. To prevent this infection, education of the public is vital. The nurse should educate the parents on ensuring that the children are vaccinated against neisseria meningitides. All contacts should be educated about the signs and symptoms of the infection and when to return to the emergency room (Munguambe, 2018)

The nurse should be explained the procedure and its risks to the patient and informed consent obtained if relevant in the practice setting. The description should include how the procedure will be performed, why it is being performed, what complications may occur, and how these can be treated. (Gibb, 2018)

The nursing teaching program provides a comprehensive plan that demonstrates the feasibility of the program and ensures that nurses are able to meet the applicable standards and competencies. The nursing teaching program provides its content that ensures receive the theoretical and clinical practice experiences required to meet the applicable standards and competencies. The program provides quality to nurses in order to meet the applicable standards and competencies. The nursing teaching program has formal systems and processes in place to measure nursing performance as well as program effectiveness. (Standards for Nursing Teaching Programs, 2018) 


\section{Significance of the study}

The incidence of acute bacterial meningitis often depends on isolation of bacteria on culture which may take $24-48$ hour, morbidity and mortality rates are even highly in developing continues rapid. Therefore nurses needs to teaching program to increase the knowledge and skills and able to deal with acute meningitis patients. Statistics report of acute meningitis at emergency unite in 170 cases in1sep-2016 to 1-sep-2017 (hospital record at Assiut university Hospital)

\section{Aim of the study}

The aim of this the study was to evaluate the effect of teaching program about nursing care of acute meningitis on nurses performance at emergency units.

\section{Research Hypothesis}

- There was a statistical significance difference between post-test nurse's knowledge scores to the pretest nurse's knowledge scores after implementation of education program.

- There was a statistical significance differences between post-test nurse's skills scores to the pretest nurse's skills scores after implementation of education program.

- Positive relation was exist between nurse's knowledge and skills score obtained by teaching program.

\section{Subjects \& Method}

Research design; Quasi -experimental research design was utilized in this study with one group prepost test approach.

Setting of the study; the study was conducted in emergency unit is consist of ten room, one for the examination, one ER intermediate care and eight for hospitalized patient at Assiut university hospital. Sample; Convenient sample of all nurses staff working in selected setting (30 nurses) were include in the study.

Tools and data collection:-Tow tools were used this study.

Tool one ( assessment interview sheet ): This tool consisted of open question structured prelpost test questionnaire tool; This tool was developed by the investigator after reviewing of literature (Al-wily 2018, Attia 2014) to assess the knowledge level of critical care nurses regarding acute meningitis .It was in Arabic language. This tool will divided into two main parts.

Part 1: Nurses demographic data such as age, sex, residence, marital status, and educational level (5closed ended question's)
Part 2: This part consist of 26 open questions covering three main parts:-

-Basic knowledge about anatomy and physiology of the component and function of central nervous system, definition, microbe causes, signs and symptoms, incubation period, disease transfusion, eliminate the inflammation of meningitis, It consist of "8"eight open questions.

-Basic knowledge about diagnosis, lumber puncture and precaution, benefit of vaccine gram , causes of relapse, complication of vaccine contraindication and factors, It consist of "9"nine open questions.

-Basic knowledge about complication, types, treatment, causes improvement, prevention method, nutrition, hand washing and universal precaution, It consist of "9"nine open questions.

Scoring system for nurse's knowledge: all questions (26) of 100 degree had three alternative answers .A score value of (2) was complete correct answer, (1) was incomplete correct answer and (0) was don't know.

Total score of nurse's knowledge was calculated and classified as follows: less than (65 degree ) $60 \%$ unsatisfactory and more than (65 degree) $60 \%$ satisfactory based on statistical analysis .

Tool two (skills assessment tool): This tool consist of observational Checklist sheet for assessment of the nurses skills, it covered all the steps procedure of nursing care for patients with Lumber Puncture, This tool was adopted from 2016Advanced Health Practitioner comprised of 12 steps.

Scoring system for nurse's skill: The total score for all steps were 12 with 24 degree and every step evaluated as follows: not done was scored (0), incorrectly done was scored (1) and correctly done was scored (2).

Total score of nurse's skills was calculated and classified as follows: less than(15 degree) $60 \%$ unsatisfactory and more than (15 degree)60\% satisfactory based on statistical analysis .

Construction of the teaching program:

The teaching program of meningitis was developed by the researcher based on the previous assessment of nurse's knowledge and skills, available resources and review of relevant literature 'Al-wily 2018, Attia 2014.

General objective of the program

The overall objective of the developed programs to was to evaluate the effect of teaching program about nursing care of acute meningitis on nurses performance at emergency units.

Specific objective of the program; by the end of the program nurses were able to: Knowledge and understanding skills: will be covered identify the anatomy of central nervous system, identify the physiology of central nervous system, define acute 
meningitis and recognize signs that indicate acute meningitis diagnosis, identify vaccine it benefits, identify complication of vaccine\& contraindication, identify complication \&treatment of acute meningitis ,identify causes improvement \& prevention method, identify nutrition that important in acute meningitis, recognize hand washing \& universal precaution with acute meningitis patient. Intellectual skills: covered classify types of acute meningitis, identify disease transfusion, identify incubation period and identify how to eliminate the inflammation of acute meningitis. Professional skills: Identify lumber puncture procedure $\&$ precaution

\section{General and transferable skills}

-Communicate effectively with team work.

-Protect the equipment at the lumber puncture unit.

\section{Method}

Pilot study A pilot study was be carried out for testing data collection on $10 \%$ from nurses ( 8 of them) included in the main study in order to test the clarity and applicability of including question and statement, content, feasibility and consistency of the tool to detect any ambiguity in the study tools. The pilot study has also served to estimate the time required to fill the form. It was included in the sample, The reliability was test for tool one (knowledge assessment tool 0.859), tool tow (skill assessment tool 0.875) by using Cronbach's coefficient alpha score.

Ethical consideration

-Research proposal will be approved from Ethical Committee in the Faculty of Nursing, There is no risk for study subject during application of the research, The study will follow common ethical principles in clinical research ,Written consent will be obtained from patient's or guidance that are willing to participate in the study after explaining the nature and purpose the study, Confidentiality and anonymity will be assured, Study subject have the right to refuse to participate and or withdraw from the study without any time, Study subject privacy will be considered during collection of data.

The study Was conducted on three phases (preparing phase, implementation phase and evaluation phase).

\section{Preparing phase}

-Permission to conduct the study was obtained from the hospital responsible authorities after explanation of the aim of study.

-Tool one used in this study was developed in Arabic by the researcher based on reviewing the relevant literature (Al-wily2018, Attia 2014)

-The tool ware tested for content related validity by jury of five specialists in the field of critical care nursing.
-Permission for voluntary participation was obtained from nurses after the purpose of the study was explained.

-An approval was obtained from the local ethical committee and the study was followed the common ethical principles in clinical research.

-Development of the teaching program: The teaching program was developed by researcher, after reviewing the relevant literature'Al-wily2018, Attia 2014' the following steps were adopted develop the program:

- Stating the program general and specific objectives.

- Planning the program: the content of the program were arranged into four teaching session in addition to preliminary one.

The content of the program covered two parts related to:

- Knowledge about Acute Meningitis and its nursing management.

- Performance of procedure required acute meningitis (Lumber Puncture)

Theoretical part included: Anatomy and physiology central nervous system, define acute meningitis, define signs that indicate acute meningitis, Classify types of acute meningitis, Identify disease transfusion, Identify incubation period, Identify how to eliminate the inflammation of acute meningitis, Diagnosis of acute meningitis, Identify lumber puncture procedure and precaution, Identify vaccine it benefits, Identify complication of vaccine and contraindication, Identify complication \& treatment of acute meningitis, Identify causes improvement and prevention method, Identify nutrition that important in acute meningitis, Recognize hand washing and universal precaution with acute meningitis patient.

practical part included:-Lumber Puncture procedure.

Learning environment:-The program was conducted nurse's at room in emergency unite at assiut university hospital.

Teaching methods: Lectures and discussion by using audiovisual aids:

-Power Point presentation and booklet which developed in Arabic by the researcher based on reviewing the related literature Al-wily2018 Attia,2014).

-Videos and Poster about acute Meningitis and Lumber Puncture Procedure.

Arranging the subgroup: The total sample was divided into ten subgroups included three nurses each session for better understanding.

Implementation phase: -All nurses were interviewed during break time (one hour) in different shifts or before beginning of shift. 


\section{Assessment of knowledge was done pre \&post as follows:}

-Once at beginning of study was considered as pretest assessment and as base line data for letter comparison with future posttest. -The second administration of questionnaire was carried out after implementation of the teaching program to identify its effect on nurse's knowledge.

Assess nurse's skill :- The researcher observes the nurses skill using observational checklist tool twice pre and immediately post program implementation.

\section{Implementation of program:}

The program was implemented for the ten subgroups of the nurses, All groups were exposed to five sessions every session takes 45 minutes , 10 minutes for revision and 5 minutes for summary. In addition to the preliminary session. Preliminary session: in this session the researcher met the participants and explained the objective, content and method of evaluation of program. (Theoretical part) Session 1 include: Information about anatomy and physiology of central nervous system, definition of meningitis, signs and symptoms and risk factors. Session 2 included: Information about effect of meningitis on patient and types. Session $\mathbf{3}$ included: Information about diagnosis\& medical management including, dietary, fluid and rest and sleep mange. Session 4 included: Nursing management including keep the room as quiet as possible and keep environmental stimuli at a minimum (Practical part) Session 5 included: Information about lumber puncture procedure. Group discussion was encouraged with continuous feedback to ensure understanding and achievement of the septic objective of the program. An open channel of communication was established between the researcher and nurses to answer any question and reinforce the gained information and correct action. In the last session the researcher summarized and emphasized the important point.

Evaluation phase: The evaluation of program was carried out immediately after the end of the teaching program using the pre-posttest study tools one(questionnaire about Acute Meningitis ) and tool two (observation checklist about Lumber Puncture ) in order to test the effectiveness of the program on nurse's knowledge and performance. Data was collected by the researcher during approximately eight months starting from December 2017 to July 2018.

Statistical analysis

- The data entry and data analysis were done using (SPSSVer.19)

- Descriptive statistics (number, percentage, mean and standard deviation) were done.

- Chi-square test was done to compare qualitative variable between pre and post group.

- Independent samples t-test was done to compare quantitative variable between pre and post group.

- Pearson correlation between quantitative variable.

- P-value considered statistically significant when $\mathrm{P}<0.05$.

\section{Results}

Table (1): The Socio- demographic data of studied nurses $(n=30)$

\begin{tabular}{|l|c|c|}
\hline \multicolumn{1}{|c|}{ Socio- demographic data } & No & \% \\
\hline Age & & \\
\hline$>25$ years & 17 & 56.7 \\
\hline$\leq 25$ years & 13 & 43.3 \\
\hline Mean \pm S(range) & \multicolumn{2}{|c|}{$25.3 \pm 5.5(18-37)$} \\
\hline Residence & 11 & 36.7 \\
\hline Rural & 19 & 63.3 \\
\hline Urban & & \\
\hline Gender & 30 & 100.0 \\
\hline Female & & 43.3 \\
\hline Marital Status & 13 & 56.7 \\
\hline Single & 17 & 30.0 \\
\hline Married & & 10.0 \\
\hline Educational Level & 9 & 43.3 \\
\hline Medium education & 3 & 16.7 \\
\hline Health Technician institute & 13 & \\
\hline Nursing Technician institute & 5 & \\
\hline Bachelor of Nursing & \multicolumn{2}{|c|}{} \\
\hline
\end{tabular}




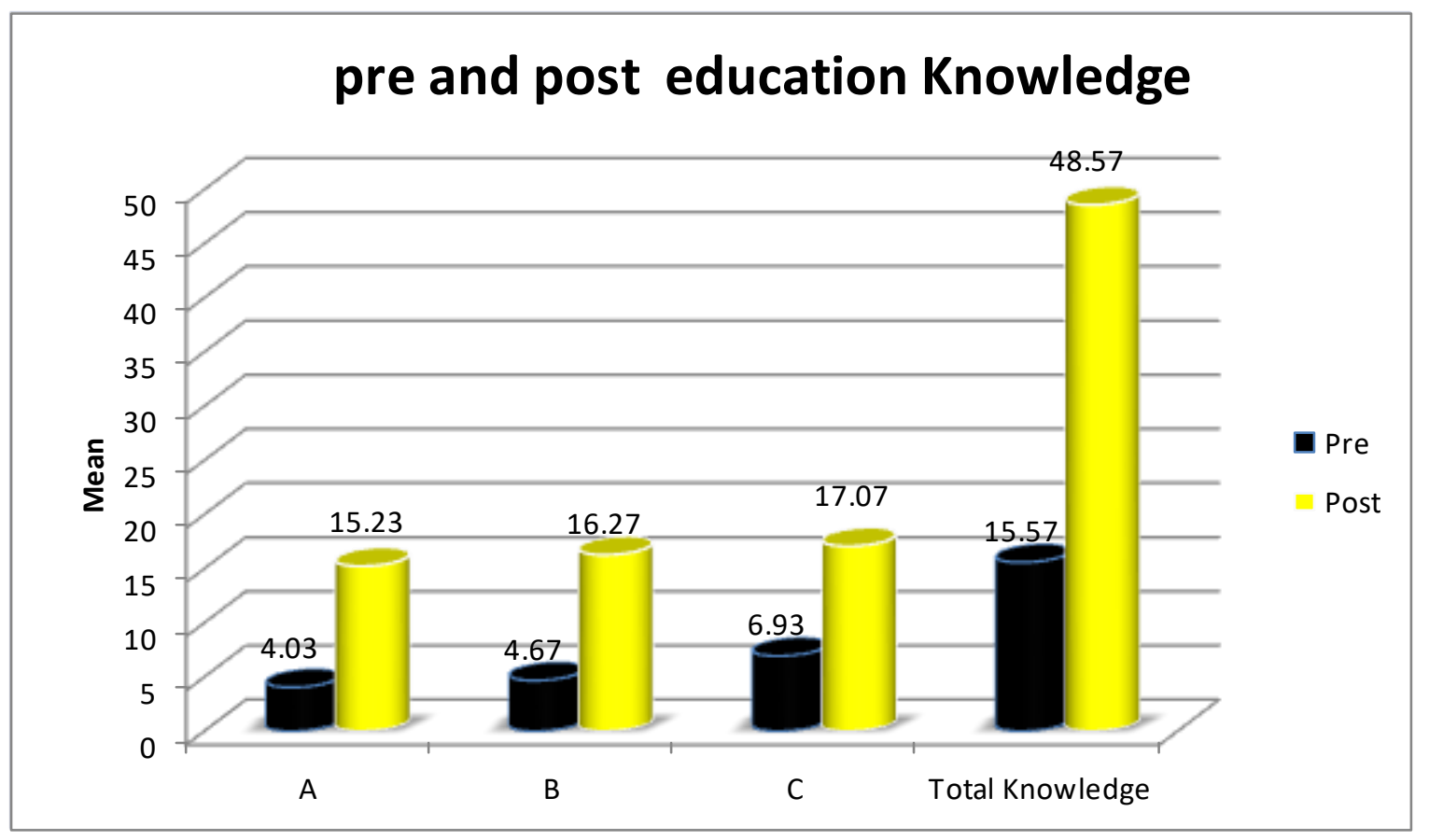

Figure (1): The Total Score of Nurses Knowledge pre and post teaching program

Table (2): percentage distribution of the total score of nurses Knowledge Level through the program phase (pre and post education)

\begin{tabular}{|c|c|c|c|c|c|}
\hline \multirow{2}{*}{ Knowledge Level } & \multicolumn{2}{|c|}{ Pre } & \multicolumn{2}{|c|}{ Post } & \multirow{2}{*}{ P. value } \\
\hline & No & $\%$ & No & $\%$ & \\
\hline Unsatisfactory & 28 & 93.3 & 0 & 0.0 & \multirow{3}{*}{$<0.001 * *$} \\
\hline Satisfactory & 2 & 6.7 & 30 & 100.0 & \\
\hline Total & 30 & 100.0 & 30 & 100.0 & \\
\hline Mean \pm SD & \multicolumn{2}{|c|}{$15.57 \pm 8.18$} & \multicolumn{2}{|c|}{$48.57 \pm 1.91$} & $<0.001 * *$ \\
\hline
\end{tabular}

Test type - Chi-square test, ** statistical Significant difference at $p$. value $<0.01$ $\&$ independent $t$-test $* *$ statistical Significant difference at $p$. value $<0.01$

Table (3): percentage \&relationship between practice items (pre \&post education.

\begin{tabular}{|c|c|c|c|c|c|c|c|c|c|c|c|c|c|c|}
\hline \multirow{3}{*}{ Items } & \multicolumn{6}{|c|}{ Pre } & \multicolumn{6}{|c|}{ post } & \multirow{3}{*}{$\mathbf{X} 2$} & \multirow{3}{*}{ P. value } \\
\hline & \multicolumn{2}{|c|}{ Not Done } & \multicolumn{2}{|c|}{ Not correct } & \multicolumn{2}{|c|}{ correct } & \multicolumn{2}{|c|}{ Not Done } & \multicolumn{2}{|c|}{$\begin{array}{c}\text { Not } \\
\text { correct }\end{array}$} & \multicolumn{2}{|c|}{ correct } & & \\
\hline & No & $\%$ & No & $\%$ & No & $\%$ & No & $\%$ & No & $\%$ & No & $\%$ & & \\
\hline \multicolumn{15}{|l|}{ Pre procedure } \\
\hline $\begin{array}{l}\text { Explain the } \\
\text { procedure to the } \\
\text { patient }\end{array}$ & 22 & 73.3 & 8.0 & 26.7 & 00.0 & 00.0 & 0 & 00.0 & 1.0 & 3.3 & 29.0 & 96.7 & 56.444 & $<0.001 * *$ \\
\hline Hand washing & 22 & 73.3 & 8.0 & 26.7 & 00.0 & 00.0 & 0 & 00.0 & 1.0 & 3.3 & 29.0 & 96.7 & 56.444 & $<0.001 * *$ \\
\hline Maintain the privacy & 0 & 00.0 & 0.0 & 0.0 & 30.0 & 100.0 & 0 & 00.0 & 0.0 & 0.0 & 30.0 & 100.0 & --- & --- \\
\hline $\begin{array}{l}\text { prepare the } \\
\text { equipment }\end{array}$ & 0 & 00.0 & 30.0 & 100.0 & 00.0 & 00.0 & 0 & 00.0 & 3.0 & 10.0 & 27.0 & 90.0 & 49.091 & $<0.001^{* *}$ \\
\hline \multicolumn{15}{|l|}{ During procedure } \\
\hline $\begin{array}{l}\text { put the patient in } \\
\text { suitable position } \\
\text { positioned on one } \\
\text { side at the edge of } \\
\text { the bed with the } \\
\text { thigh and legs are } \\
\text { flexed as much as }\end{array}$ & 0 & 00.0 & 30.0 & 100.0 & 0.0 & 00.0 & 0 & 00.0 & 1.0 & 3.3 & 29.0 & 96.7 & 56.129 & $<0.001 * *$ \\
\hline
\end{tabular}




\begin{tabular}{|c|c|c|c|c|c|c|c|c|c|c|c|c|c|c|}
\hline \multirow{3}{*}{ Items } & \multicolumn{6}{|c|}{ Pre } & \multicolumn{6}{|c|}{ post } & \multirow{3}{*}{$\mathbf{X} 2$} & \multirow{3}{*}{ P. value } \\
\hline & \multicolumn{2}{|c|}{ Not Done } & \multicolumn{2}{|c|}{ Not correct } & \multicolumn{2}{|c|}{ correct } & \multicolumn{2}{|c|}{ Not Done } & \multicolumn{2}{|c|}{$\begin{array}{c}\text { Not } \\
\text { correct }\end{array}$} & \multicolumn{2}{|c|}{ correct } & & \\
\hline & No & $\%$ & No & $\%$ & No & $\%$ & No & $\%$ & No & $\%$ & No & $\%$ & & \\
\hline \multicolumn{15}{|l|}{ possible > } \\
\hline $\begin{array}{l}\text { the nurse assist the } \\
\text { patient to maintain } \\
\text { the position to avoid } \\
\text { sudden movement }\end{array}$ & 0 & 00.0 & 30.0 & 100.0 & 0.0 & 00.0 & 0 & 00.0 & 0.0 & 00.0 & 30.0 & 100.0 & 60.000 & $<0.001 * *$ \\
\hline $\begin{array}{l}\text { encourage the } \\
\text { patient to relax and } \\
\text { breath normally }\end{array}$ & 28 & 93.3 & 2.0 & 6.7 & 0.0 & 00.0 & 0 & 00.0 & 1.0 & 3.3 & 29.0 & 96.7 & 57.333 & $<0.001 * *$ \\
\hline $\begin{array}{l}\text { the physician clean } \\
\text { the site with } \\
\text { antiseptic solution }\end{array}$ & 0 & 00.0 & 30.0 & 100.0 & 0.0 & 00.0 & 0 & 00.0 & 0.0 & 00.0 & 30.0 & 100.0 & 60.000 & $<0.001 * *$ \\
\hline $\begin{array}{l}\text { the physician inject } \\
\text { the local anesthetic } \\
\text { agent and than insert } \\
\text { needle to } \\
\text { subarachnoid space } \\
\text { through } 3 \text { rd and } 4 \text { th } \\
\text { or 4th and } 5 \text { th } \\
\text { Lumber inter space }\end{array}$ & 0 & 00.0 & 30.0 & 100.0 & 0.0 & 00.0 & 0 & 00.0 & 0.0 & 00.0 & 30.0 & 100.0 & 60.000 & $<0.001 * *$ \\
\hline $\begin{array}{l}\text { Specimen of CSF is } \\
\text { collected in test tube } \\
\text { than the needle is } \\
\text { withdraw than } \\
\text { applies small } \\
\text { dressing to the } \\
\text { present site than the } \\
\text { tube of CSF is sent } \\
\text { to Laboratory } \\
\text { immediately }\end{array}$ & 0 & 00.0 & 30.0 & 100.0 & 0.0 & 00.0 & 0 & 00.0 & 1.0 & 3.3 & 29.0 & 96.7 & 56.129 & $<0.001 * *$ \\
\hline \multicolumn{15}{|l|}{ Post procedure } \\
\hline $\begin{array}{l}\text { instruct the patient } \\
\text { to lie in prone } \\
\text { position to reduce } \\
\text { leak of CSF and } \\
\text { observe any } \\
\text { complication if } \\
\text { occurred }\end{array}$ & 30 & 100.0 & 0.0 & 00.0 & 0.0 & 00.0 & 0 & 00.0 & 0.0 & 00.0 & 30.0 & 100.0 & 60.000 & $<0.001 * *$ \\
\hline $\begin{array}{l}\text { Encourage increased } \\
\text { fluid intake prevent } \\
\text { post procedure } \\
\text { headache }\end{array}$ & 30 & 100.0 & 0.0 & 00.0 & 0.0 & 00.0 & 0 & 00.0 & 0.0 & 00.0 & 30.0 & 100.0 & 60.000 & $<0.001 * *$ \\
\hline
\end{tabular}

Test type Chi-square test

** Significant difference at $p$. value $<0.01$

Table (4): Comparison between pre and post education According to Subdomain of Practice.

\begin{tabular}{|l|c|c|c|c|c|c|}
\hline \multicolumn{1}{|c|}{ Group } & No of items & score & Pre & post & T & P. value \\
\hline Pre procedure & 4 & 8 & $3.53 \pm 0.51$ & $7.83 \pm 0.38$ & -37.186 & $<0.001^{* *}$ \\
\hline During procedure & 6 & 12 & $5.07 \pm 0.25$ & $11.9 \pm 0.31$ & -94.318 & $<0.001^{* *}$ \\
\hline Post procedure & 2 & 4 & $0 \pm 0$ & $4 \pm 0$ & - & - \\
\hline Total practice score & 12 & 24 & $8.6 \pm 0.56$ & $23.73 \pm 0.45$ & -114.997 & $<0.001^{* *}$ \\
\hline
\end{tabular}

Test type independent t-test ** Statistical Significant difference at $p$. value $<0.01$

Section 3: the testing research hypothsese2:-The additional correlational Finding.

Table (5) Present the correlation between Practice score\& Knowledge score in pre and post test.

\begin{tabular}{|l|c|c|}
\hline \multirow{2}{*}{ Total Practice score } & $\mathrm{R}$ & Total Knowledge score \\
\cline { 2 - 3 } & 0.376 & $\mathrm{P}$ \\
\hline Pre Education & 0.545 & $0.017^{*}$ \\
\hline Post Education & \multicolumn{2}{|c|}{} \\
\hline Test type; Pearson correlation & $* *$ Significant difference at p. value $<0.001$ \\
\hline
\end{tabular}




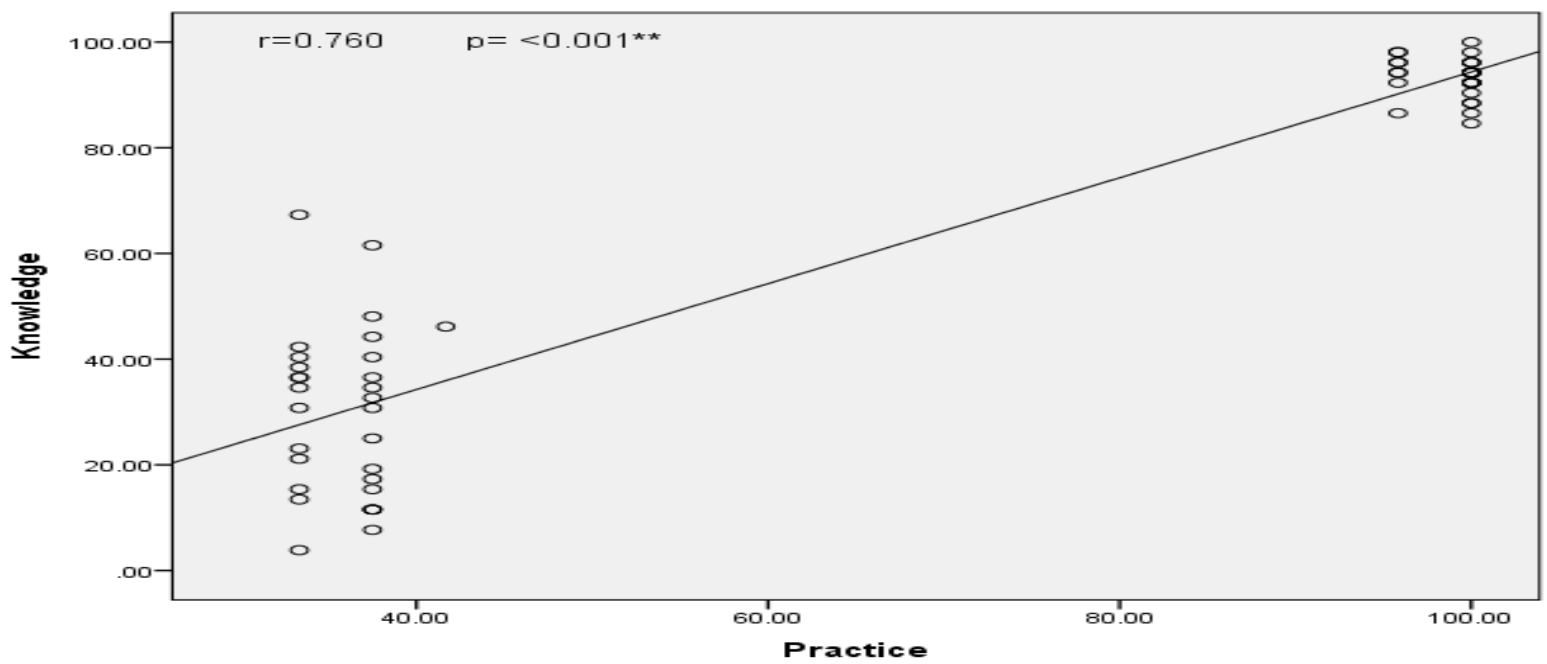

Figure 2: The Correlation between score of nurses Knowledge with practice in post teaching program .

Table (6):- Relationship between Knowledge Score According to socio demographic data before and after teaching program.

\begin{tabular}{|c|c|c|c|c|}
\hline \multirow{3}{*}{ socio demographic } & \multicolumn{4}{|c|}{ Knowledge Score } \\
\hline & \multicolumn{2}{|c|}{ Before teaching } & \multicolumn{2}{|c|}{ After teaching } \\
\hline & Mean \pm SD & Range & Mean \pm SD & Range \\
\hline \multicolumn{5}{|l|}{ Age group } \\
\hline $18-25$ years & $14.59 \pm 6.44$ & $4-23$ & $48.94 \pm 1.98$ & $44-52$ \\
\hline more than 25 & $16.85 \pm 10.11$ & $2-35$ & $48.08 \pm 1.75$ & $45-51$ \\
\hline P.value & \multicolumn{2}{|c|}{0.462} & \multicolumn{2}{|c|}{0.225} \\
\hline \multicolumn{5}{|l|}{ Residence } \\
\hline Rural & $13.09 \pm 7.01$ & $2-24$ & $49 \pm 2.49$ & $44-52$ \\
\hline Urban & $17 \pm 8.6$ & $4-35$ & $48.32 \pm 1.49$ & $45-51$ \\
\hline P.value & \multicolumn{2}{|c|}{0.211} & \multicolumn{2}{|c|}{0.352} \\
\hline \multicolumn{5}{|l|}{ Marital Status } \\
\hline Single & $16.38 \pm 7.85$ & $4-32$ & $49.08 \pm 1.85$ & $44-52$ \\
\hline Maried & $14.94 \pm 8.56$ & $2-35$ & $48.18 \pm 1.91$ & $45-51$ \\
\hline P.value & \multicolumn{2}{|c|}{0.639} & \multicolumn{2}{|c|}{0.205} \\
\hline \multicolumn{5}{|l|}{ Educational Level } \\
\hline Medium education & $17.78 \pm 8.7$ & $8-35$ & $48.11 \pm 2.26$ & $45-51$ \\
\hline Health Techniciian institute & $18.33 \pm 1.53$ & $17-20$ & $46.67 \pm 2.52$ & $44-49$ \\
\hline Nursing Techniciian institute & $14.62 \pm 9.07$ & $4-32$ & $49 \pm 1.53$ & $46-52$ \\
\hline Bachelor of Nursing & $12.4 \pm 7.09$ & $2-19$ & $49.4 \pm 1.14$ & $48-51$ \\
\hline P.value & \multicolumn{2}{|c|}{0.608} & \multicolumn{2}{|c|}{0.161} \\
\hline
\end{tabular}

Table (1): Shows the demographic data of studied nurses: It was found that more than half of group ware aged from 18 to <25years with percentage $56.7 \%$ while group ware age more than 25 years with percentage $43.3 \%$. Concerning their residence with urban percentage $63.3 \%$ while rural percentage $36.7 \%$.Gender of group study were female with percentage $100 \%$ and $56 \%$ were married. Moreover their educational level $30 \%$ of nurses held Medium education, $10 \%$ health teaching institute, 43.3\% Nursing Technician institute its highly percentage while $16.7 \%$ of the nurses held Bachelor of Nursing.

Table (2): Shows the result was found that highly statically difference between nurses knowledge between (pre studied \& post studied) groups. PostKnowledge post studied group had satisfactory level with percentage (100\%)

Table (3): Shows the percentage \&relationship between practice items pre \&post education, it was observed that there statistical significant difference in all items in this table. 
Table (4): Shows the Comparison between pre and post education the percentage distribution according to subdomain of practice Pre procedure before $3.53 \pm 0.51$ after7.83 \pm 0.38 . During procedure before $5.07 \pm 0.25$ after $11.9 \pm 0.31$. After procedure before $8.6 \pm 0.56$ after $23.73 \pm 0.45$.

Table (5): Shows the Percentage the correlation between Practice score \& Knowledge score in pre and post test, there was significant positive correlation between Practice \& Knowledge in pre and post teaching program (r value 0.760 ) respectively .

Table (6): Presents the relationship between total score of nurses knowledge and socio demographic characteristic, Pre teaching program, showed that, There was no statistical significant difference between pre-program knowledge of nurses and their socio demographic characteristics used Independent T- test \& Anova test ,P-Value Before the program was (0.608) and after the program (0.161).

Figure (1): Shows the Total Score of Nurses Knowledge (93.3\%) in pre and $(100 \%)$ in post teaching program.

A: Measurement of nurses knowledge about (the component\&, function, of central nervous system ,definition, microbe causes, signs \&symptoms, incubation period, disease transfusion, eliminate the inflammation of meningitis

B: nurses knowledge about(Diagnosis , lumber puncture \& precaution, vaccine it benefit, causes of relapse , complication of vaccine contraindication, factors) \&

C: Measurement of nurses knowledge about (complication ,types ,treatment , causes improvement , prevention method, nutrition, hand washing and universal precaution.

Figure (2): Shows the Correlation between score of nurses Knowledge with practice in post teaching program.

\section{Discussion}

Nursing Care management for patients needs the nurse should take the necessary precaution to protect themselves and other from possible infection teach parents the proper procedure and supportive them in the application. (Maya, 2014)

As regard of the nurses demographic characteristic. The Current study presented that the Age of nurses are (18-25) years' with more half fifty percent and for more than 25 years with nearly half fifty percent this finding are supported with the finding of (Al wily, 2015) who reported that more of the sample was at the age of (18-25) years also. These study can ducted by (Alsaidy, 2016) which stated that half of his sample were nurses with age (23-32 ) years old. Gender of nurses: The analysis of finding in the table (1) ravels that all the group (study group) were female these results agree with findings of ( Abbas, 2012) who found the highest percentage of his study sample were female nurses . Additional support is found by( Al wily, 2015) who found the majority of his sample were female also .

As regard of nursing level of education: The results reveal that the majority of the nurses for (study group) were graduated from the nursing technical Institute with $(43.3 \%)$ these finding agree with the (Salih, 2016) who stated in his study the nurses were graduated from technician institute, but discharge with the (Alsaidy,2016) who observed the majority of sample were graduated from the second nursing school.

As regard Effectiveness of education program on nurses knowledge toward acute meningitis (pre-post test) The present study figured out the, the level of knowledge of the majority of studied nurses generally through program phase (pre-post) education had satisfactory level with percentage $(100 \%)$, this with for pre test with $(67 \%)$ while for post test $(100 \%)$ that duo to cause problems for them to learn another cause for lack of knowledge is that the most of them ,were not receiving any teaching program for continues update their knowledge about acute meningitis. So, concerning nurses knowledge regarding meningitis the current study reveal in table, that total mean score of nurses knowledge pre and post teaching program had significance difference about acute meningitis P.value $(<0.001)$. This result supported by (Attia, 2014) who found in their study that nurses knowledge regarding to acute meningitis is poor knowledge this might duo to lack of continues education for these nurses in addition lack of motivation to updating their knowledge.

As regard the answer of nurses about lumber puncture procedure in the pre test teaching program incomplete correct more half fifty percent while in the post test with complete correct the most this agree with (Parthosorathly, 2013) who reveal in his study were the level of incomplete correct knowledge about the benefits of vaccine with the post test for the study group.

As regard Comparative Difference in nurses knowledge to ward pre-post test for study group. The effectiveness of education program on nurses knowledge to ward acute meningitis show as seen as in the table that the results refer to highly significant difference among nurses knowledge in the study group at P.v $=0.001$ respectively . The results above agree with study done by (Southwick, 2013) who found that high significance associated with pre-post test with p.v $<=0.001$, while (Ward, 2014) who found significant relationship between nurses knowledge to ward acute meningitis (pre-post test). 
As regarding to positive relation will exist between to total score of nurses of knowledge and skills score that obtained by critical care receiving teaching program that shown there was a significant positive correlation lecture total score of nurses knowledge related to total score skill of Lumber Puncture after teaching program $($ T.value $=0.760)$ respectively As regarding to the relationship between total score of nurses knowledge and socio demographic characteristics post test program shown that it was no statistical difference between post nurses knowledge and socio demographic characteristics. At P.value <= (0.05), that supported with (Jissirs, 2015) who indicated no significant relationship.

\section{Conclusion}

The majority of nurses had satisfactory knowledge and skills toward nursing care of acute meningitis after applying of teaching program more than before implementation it with statistical significant differences between pre test and post test of teaching program.

\section{Recommendations}

Based on the study findings, the following recommendations are suggested:-

-The latest guidelines of acute meningitis should be available in written format in critical units and generally units.

-The risk factors, causes and prevention measures of acute meningitis should be integrated in schools and the undergraduate nursing curriculum.

\section{References}

1. Abbas, F., (2012): Effectiveness of an Educational Health Program on Pediatric Nurses' Knowledge and Practices toward Children under Mechanical Ventilation in Pediatric Teaching Hospitals at Baghdad City, A Thesis Submitted By. University of Baghdad / college of nursing. Published master thesis , pp: 67-72.

2. Alsaidi, K., (2006): Assessment of Nurses' Knowledge toward Child with Bacterial Meningitis at Pediatric Teaching Hospitals in Baghdad City, a Thesis Submitted By. University of Baghdad / college of nursing. Published master thesis: p.p 238-253.

3. Al-wily, M., (2015): Effectiveness of Educational Program on Nurses Knowledge toward Nosocomial Infection at Neonate Intensive Care Units in Baghdad Hospitals, A Thesis Submitted By, University of Baghdad / college of nursing. Published master thesis : pp79-88.
4. Attia J., Hatala R., Cook D., Wong J., (2014): The rational clinical examination. Does this adult patient have acute meningitis? Journal of the American Medical Association 282(2): p.p 175-181. doi:10.1001/jama.282.2.175. PMID 10411200.

5. Gibb, W., \& Wen, P., (2018): Current practice of diagnostic lumbar puncture. Br Med J, P.P 289: 530 .

6. Jissir, S., \& Hassan, H., (2015): Effectiveness of an Educational Program on Nurses Knowledge about Nosocomail Infection: CaseControl Study. Kufa Journal for Nursing Sciences, 5(1).pp.5-8.

7. Leonard A., Lalk M., (2018): Infection and metabolism - Streptococcus pneumoniae metabolism facing the host environment. "Difficult and recurrent meningitis" (PDF).Journal of Neurology, Neurosurgery, and Psychiatry. 75 Suppl 1 (90001): i16-21. doi:10.1136/jnnp.2003.034272. PMC 1765649 Freely accessible. PMID 14978146. Archived (PDF) from the original on $01 \mathrm{Aug}$ 2018.

8. Louis D., Saravolatz, Odette Manzor, Bradely Belian, (2017): St, Johan Hospital and Medical Center: , v, No 22201. pp 222-231.

9. Marilyn, Hockenberry, (2017): Wong's Essentials of pediatric nursing, thenth Edition, print in Canada: p.p 891-893.

10. Meya D., Carlson R., Rolfes M., Birkenkamp K., Nakasujja N., Rajasingham R., (2014): Predictors of neurocognitive outcomes on antiretroviral therapy after cryptococcal meningitis: A prospective cohort study. Metab Brain Dis: p.p 2921-2979.

11. Munguambe A., de Almeida A., Nhantumbo A., Come C., Zimba T., Paulo Langa J., de Filippis I., Gudo E., (2018): Characterization of strains of Neisseria meningitidis causing meningococcal meningitis in Mozambique,Implications for vaccination against meningococcal meningitis. PLoS ONE. 2018;13(8): pp 563-581.

12. Parthasarathy, A., (2013): Textbook of pediatric infectious diseases. JP Medical Ltd: pp 371-374.

13. Salih, Y., (2016): Assessment of the Pediatric Nurses' Knowledge And Practices Toward Oral Mucositis In Children Under Chemotherapy in Baghdad Pediatric Hospitals, , A Thesis Submitted By, University of Baghdad / college of nursing. Published master thesis: p.p 57-67.

14. Southwick, F., (2013): Infectious Diseases A Clinical Short Course 3/E. McGraw Hill Professional: . http://www.accessmedicine.com. 
Accessed Nov. 19, 201. Acute bacterial meningitis. Merck Manual Professional Version. p.p 279-305.

15. Ward, S., Hensley's . (2014): Pediatric Nursing Care, FA Davis. Philadelphia: Streptococcus pneumonia, Neisseria meningitidis and Haemophilus influenza meningitis diagnosis," BMC Infectious Diseases, vol. 13, no. 1, article 26, pp 458-459.

16. https://www.crnm.mb.ca/uploads/ck/files/Sta ndards for Nursing Teaching Programs 20 July 2018.pdf at 02:15 Pm. 